\title{
Economia Política do Zika: Realçando relações entre Estado e cidadão
}

\author{
Ana Cláudia Rodrigues da Silva ${ }^{a}$ \\ Silvana Sobreira de Matos ${ }^{\mathrm{b}}$ \\ Marion Teodósio de Quadros ${ }^{\mathrm{c}}$
}

\begin{abstract}
A epidemia do Zika e sua relação com o nascimento de crianças com microcefalia trouxeram grandes desafios para a saúde pública mundial. No Brasil vários esforços foram feitos para minimizar suas consequências mobilizando setores importantes da saúde, da ciência, da indústria farmacêutica e da economia familiar. Este artigo pretende discutir a economia política do Zika focando nas relações estabelecidas entre Estado e cidadão no que se refere aos cuidados e atendimentos. Enfoca o contexto de vulnerabilidade das famílias afetadas num processo de sobreposição de desigualdades sociais e econômicas, em que as mulheres, mães e cuidadoras, carregam o maior peso social da epidemia.
\end{abstract}

Zika; Economia; Saúde.

Em um período de grande visibilidade internacional para o Brasil, realização da Copa do Mundo, em 2014 e das Olimpíadas, em 2016, o vírus Zika chamou atenção da população, do Estado e de

a Professora Adjunta do Departamento de Antropologia e Museologia e do PPGA (UFPE). Email: acrodriguess@gmail.com.

b Pesquisadora de Pós-Doutorado no PPGA (UFPE). Email: silvanasmatos@ gmail.com.

c Professora Associada do Departamento de Antropologia e Museologia e do PPGA (UFPE). Email: marionteodosio@yahoo.com. 
organismos internacionais de saúde. Com o aumento do número de casos de microcefalia e outros distúrbios neurológicos em decorrência do vírus, em 2016, foi decretado Estado de Emergência Internacional em Saúde Pública pela Organização Mundial de Saúde (OMS). Este período foi marcado por ações emergenciais do Estado e ações cotidianas da população, reconfigurando o cuidado público (Ayres 2009) e privado (Scott et al 2017a).

Surtos epidêmicos, como o da dengue e outras arboviroses, são bem conhecidos da população brasileira e requerem respostas imediatas dos gestores públicos. É no campo das respostas ou ações, as vezes não satisfatórias, que relações entre o Estado, suas instituições e os cidadãos são intensificadas. No caso da Zika, a confirmação da relação entre o vírus e o nascimento de bebês com Microcefalia, trouxe uma situação inusitada, diferente, por exemplo, da Dengue e da Chikungunya, que apesar de levar à morte, não apresentam uma má formação congênita associada (Miranda-Filho et al 2016).

Pernambuco surge, nesse cenário, como epicentro da epidemia, com alto índice de pessoas infectadas com o vírus Zika, entre 2014 e 2016. A partir de 2015 surgem os primeiros casos de bebês nascidos com microcefalia. Segundo os dados do Boletim Epidemiológico da Secretaria Estadual de Saúde, existem 438 casos confirmados e 335 em investigação, conhecidos popularmente como filhos/filhas do Zika ${ }^{1}$.

Estado com maior incidência de casos, Pernambuco também foi lócus de investigações e pesquisas científicas que apresentaram, de imediato, algumas respostas ao problema de saúde pública enfrentado pelo país. Acompanhamento clínico dos casos e as pesquisas acadêmicas possibilitaram a constatação de que os efeitos do vírus nos bebês não se restringiam apenas à microcefalia, mas também a outras alterações como epilepsia, deficiências auditivas e visuais, sendo denominada de Síndrome Congênita do Zika (SCZ). Cabe destacar que a observação das mães no cuidado diário com seus filhos trouxe importante contribuição para identificação de outras alterações (Diniz 2016; Scott et al 2017a). 
Crianças que nasceram com SCZ e suas mães passam a ser alvo de reportagens e pesquisas para identificação de um problema cujas consequências reais ainda são desconhecidas. Uma sensação de pânico se instalou em Pernambuco à medida que os casos eram notificados. Enxurradas de informações diariamente eram repassadas, em parte cobrando dos cidadãos atitudes como: mães evitem exposição ao mosquito! População, cuide da sua residência, não deixe o mosquito proliferar! A responsabilidade também é sua cidadão! Enquanto isso a população superlotava unidades de saúde em busca de atendimento.

Tornou-se comum mutirões em bairros considerados de risco, para informar a população e também cobrar a parceria do cidadão, sem a qual não se solucionariam os problemas, ou seja, o peso da epidemia, pelo menos no aspecto preventivo, deveria ser dividido entre o Estado e o cidadão. Contudo, o contexto emergencial da Zika parecia ter um forte acento geográfico, de gênero, classe e raça. A maioria dos casos incidiu mais fortemente entre as pessoas pobres de periferias, em sua maioria mulheres, negras, que por sua vez, foram as mais cobradas. Algumas ações relacionadas à gestão em saúde foram intensificadas, principalmente em Recife, como a obrigatoriedade de notificações dos casos de Zika, do nascimento de crianças com a síndrome e a efetivação do Levantamento Rápido do Índice de Infestação por Aedes aegypti (LIRAa). Tais medidas auxiliariam ações no campo do controle, prevenção e atendimento às pessoas acometidas com a doença causada pelo vírus ${ }^{2}$.

$\mathrm{O}$ Zika vírus tornou-se, numa linguagem antropológica, um fato social total, e como tal reflete uma multiplicidade de fatos e significados que vão desde a relação estabelecida com o mosquito (um ser não humano) a um dos atos humanos mais básico, o nascimento. É nesta perspectiva que abordaremos a economia política de atendimentos e cuidados do Zika, com ênfase no contexto pernambucano.

Apesar de ter sido decretado o fim da emergência em saúde pública pelo Ministério da Saúde, no dia 11 de maio de 2017, dando a entender que a situação melhorou, ainda estamos diante de problemas que 
estão longe de serem solucionados, pois, uma vez instaurados, deixaram consequências para as pessoas, a exemplo de como lidar com a carga do cuidado com crianças com SCZ e a busca pela garantia de direitos. Se, por um lado, observa-se a diminuição dos casos de Zika, por outro, há a necessidade de lidar com as pessoas que foram afetadas. Nesse sentido, a economia política do Zika requer especial atenção por movimentar setores importantes da saúde, da indústria farmacêutica, dos fomentos para pesquisas, da economia familiar, abalada diretamente por ter que lidar com uma situação inesperada, na qual questões relacionadas à subjetividade como as emoções atreladas ao cuidado (Scott et al 2017a; Meira et al 2017), o preconceito, a violação de seus direitos e a violência institucional, que se fizeram presentes nas mais diversas situações cotidianas.

Por trás das arboviroses, se forma um mercado em que o Estado brasileiro passa a ser provedor e consumidor, gerando demandas como a criação de novas vacinas, kits para detecção sorológica, financiamento de pesquisas e capacitação de profissionais. No discurso do Estado, observa-se ênfase na busca por novas tecnologias para controle do mosquito, engajamento, mobilização social e o fortalecimento de ações integradas, mas pouco tem sido feito para apoiar as famílias de crianças com SCZ, principalmente os/as cuidadores/as ${ }^{3}$.

Este artigo aborda resultados parciais da pesquisa 'Etnografando Cuidados e Pensando Política de Saúde e Gestão de Serviços para Mulheres e Seus Filhos com Distúrbios Neurológico Relacionados com Zika em Pernambuco-Brasil', realizada pelo grupo de pesquisa Família, Gênero e Sexualidade (Fages), da Universidade Federal de Pernambuco. Este grupo de pesquisadores/pesquisadoras tem trabalhado intensamente no acompanhamento das redes das mulheres afetadas pelo Zika, observando desde o contexto cotidiano dos cuidados com os filhos com SCZ, a participação em associações como a Aliança de Mães de Crianças Raras (AMAR) e União de Mães de Anjos (UMA), até a busca por serviços de saúde, social e jurídico para seus filhos, ou seja, seguindo seus itinerários terapêuticos (Alves 2015; Pinho 2012; Gerhardt 2006). No que se refere aos serviços de saúde, 
temos acompanhado o trabalho de instituições públicas e privadas acessadas pelas mulheres. Seguindo as redes que se formam em torno da Zika, acompanhamos grupos de pesquisas, eventos políticos e acontecimentos relacionados à epidemia. $\mathrm{O}$ aporte antropológico e suas variadas técnicas metodológicas de coleta e registros de dados, como entrevistas, grupos focais, auxiliam-nos em nosso objetivo principal, o de associar o conhecimento aprofundado da experiência de mulheres e suas redes familiares afetadas pelo vírus a um esforço de ampliar a sensibilidade e a resposta do sistema de saúde de uma maneira que incorpore conhecimento mútuo e práticas colaborativas.

Para melhor compreensão da proposta aqui apresentada, este artigo está dividido em duas partes, além dessa introdução e das considerações finais. Na primeira parte abordamos a economia política do Zika e outras arboviroses, buscando perceber as articulações para controle, prevenção e cuidados. Na segunda parte, buscamos compreender as redes de cuidados em torno do Zika realçando relações de poder e as conexões estabelecidas em rede.

\section{A economia política do Zika}

A população brasileira vivenciou vários surtos epidemiológicos, como o da Febre Amarela, que após período de controle voltou à cena. Atualmente três arboviroses, Dengue, Chikungunya e Zika, transmitidas pelo mosquito Aedes aegypti, têm ocupado espaço nas demandas do Estado, exigindo ações diretas ou indiretas no controle e prevenção, realçando as relações entre Estado e cidadão. Para o caso do Zika, buscamos entender o peso social (Jones \& Williams 2004), delegado aos cidadãos e as relações de accountability (Cornwall \& Shankland 2008) dos funcionários públicos, dos trabalhadores em saúde e em assistência social, e dos atores de formulação e implementação de políticas.

Para compreensão dessa relação é importante abordar a economia política da saúde como forma de compreender as várias dimensões 
que são afloradas com a temática do Zika no campo da saúde pública. Discussões atuais apontam questionamentos importantes em torno da lógica da saúde como mercadoria inserida tanto numa perspectiva de desenvolvimento econômico quanto social. Para Belluzzo (2005), a saúde como meio de acesso à vida não poderia estar atrelada a lógica da acumulação de riquezas, pois corre-se o risco de gerar uma 'insegurança permanente' para os indivíduos. Ao se definir a saúde como direito coletivo coloca-se a responsabilidade de promovê-la para o Estado, que por sua vez, inserido numa lógica de mercado, precisa atender as demandas da população. No caso brasileiro, contamos com um sistema de saúde universal, o que colocaria esse sistema afastado, até certo ponto, da lógica mercadológica, rumo à desmercantilização do acesso. Saúde como direito constitucional nos leva à discussão sobre os mecanismos de financiamentos públicos e como eles são definidos para uma maior equidade em saúde. O crescente desenvolvimento econômico do campo da saúde, altamente rentável, impulsiona a criação de grandes parques industriais fomentados pelo desenvolvimento da indústria química, farmacêutica, biotecnológica, mecânica e elétrica.

Um dos pontos destacados pelo Estado brasileiro dentro da lógica da economia política tem sido a do controle do vetor transmissor, o Aedes aegypti que, em parte, tornou-se o foco de muitas ações da vigilância sanitária brasileira. Entretanto, a vigilância sanitária não consegue absorver a demanda requerendo a colaboração de outros setores, como por exemplo, o exército brasileiro, que passou a identificar os focos de mosquitos e a participar de campanhas preventivas. Cria-se um campo de colaboração e, também, de disputa entre gestores do governo, pesquisadores e sociedade civil organizada, pela escolha das melhores formas de lidar com o mosquito, até aqui o protagonista da cena. Alguns concordam com medidas invasivas como a pulverização aérea com substâncias químicas, com a instalação de fábricas para reprodução de mosquitos geneticamente modificados e outros reforçam a necessidade de saneamento básico, uma vez que as áreas afetadas são as que não dispõem deste serviço e sofrem com a falta de água potável. 
No campo desta economia política, os/as cidadãos/ãs entram no jogo, por um lado, tentando acionar seus direitos, por outro, sendo cobrados a também compartilhar o peso da epidemia, através do controle sanitário doméstico. Várias propagandas do governo enfatizavam o papel da população na prevenção das arboviroses, em especial relacionada ao Zika. Uma grande mobilização se formou: escolas, igrejas, ONGs, todos em prol do bem comum, a eliminação do mosquito, movimentando um mercado político e econômico que realça relações de poder. Quem decide? Como decide? Qual o poder de decisão da população nesse contexto? Pode o cidadão ordinário recursar uma imposição do Estado? Estas são perguntas pertinentes quando se intersectam as dimensões dos direitos, da economia e da política no campo da saúde.

Ao acionar essas três dimensões, o Estado, baseado numa lógica de solidariedade (Viana 2007), incentiva a formação de equipes de colaboração de diversos setores da administração pública e promove, por meio desses setores, alianças com organizações da sociedade civil, com institutos de pesquisas, com agências internacionais para financiamento de pesquisas ou ações de colaboração. Em Recife, por exemplo, podemos citar o seminário Arboviroses: vigilância, promoção da saúde, prevenção e controle, realizado nos dias 08 e 09 de março de 2017, uma iniciativa da Rede Pernambucana de Municípios Saudáveis, organizado pelo Núcleo de Saúde Pública e Desenvolvimento Social (NUSP/UFPE). O evento reuniu gestores governamentais do Estado e de vários munícipios, bem como entidades de pesquisas, para pensar estratégias de enfrentamento às arboviroses em Pernambuco.

A rede conta com apoio institucional do Japão para a troca de experiências e tecnologias que promovam qualidade de vida, reforçando laços políticos e econômicos. Porém, os grupos de apoio às mães e cuidadoras de crianças com SCZ, não estavam presentes no evento. Neste caso, a solidariedade na esfera da economia política em saúde, parece não incorporar, atores fundamentais nesse processo, as pessoas acometidas pelas arboviroses, para nosso caso pelo Zika. Aqui a antro- 
pologia pode trazer muitas contribuições, uma vez que compartilha uma perspectiva da economia política que incorpora outras lógicas, no caso, a lógica das mães de criança com SCZ, não se detendo apenas na dimensão material, mas, sobretudo, na dimensão simbólica, abrindo caminho para discussão sobre uma economia do cuidado que incorpora aspectos subjetivos (Hirata 2012; Carrasco 2012).

Exemplos baseados nas experiências das mães de filhos com SCZ nos revelam como essas dimensões estão entrelaçadas. Uma mulher em idade reprodutiva, moradora de área de incidência de casos de Zika, ou seja, área no geral desprovida de políticas de saneamento, é infectada pelo mosquito durante os primeiros meses de gravidez, sem ao menos saber o que isso significará em sua vida. A espera de uma nova vida ao mundo mobiliza aspectos do plano econômico e simbólico. Ao saber que seu filho apresenta algum distúrbio neurológico em uma possível decorrência da falta de políticas públicas do Estado, que deveria proteger o cidadão, seus sonhos, planos, expectativas, são afetados e ela precisará ressignificar esse evento em sua vida (Scott 2017b; Pinheiro \& Longhi 2017).

O que cabe ao estado fazer? O que cabe aos cidadãos afetados pelo Zika? Pontos de tensão são realçados, as famílias precisam lidar com essa nova situação arcando com o peso social e econômico. As dimensões materiais e subjetivas estão em xeque, uma economia doméstica precisa ser repensada, pois não se esperava uma criança com necessidades especiais. Seu/sua filho/a precisará de atenção redobrada quase que exclusiva, suas necessidades estão para além de uma criança sem a SCZ e isso mobiliza um campo político e econômico no qual a falta de recursos destas famílias se intensifica pela perda de emprego formal (Scott et al 2017a), e o orçamento doméstico é fortemente impactado pelas inúmeras necessidades desta criança. Devido aos problemas recorrentes de disfagia, torna-se necessário o uso de suplementos alimentares extremamente onerosos, que não são distribuídos pelo Estado. Embora Pernambuco tenha sido o primeiro Estado a incorporar o Keppra (anticonvulsivante) nas farmácias do SUS, os demais remé- 
dios e materiais como oxímetros, sondas, talas, parapódios, cadeiras, fraldas, materiais de higiene pessoal, acabam por onerar em muito o orçamento doméstico destas famílias, ultrapassando os limites do que estas conseguem por meio de doações, fornecimento pelo sistema de saúde, filantropia e apoio social, empurrando-as ainda mais para a vulnerabilidade econômica e social (Scott et al 2017b)

Ao perceberem que não darão conta, as mães recorrem às associações como AMAR e UMA, que a partir de suas experiências em lidar com o Estado as auxiliam em busca de seus direitos. Como mostra Scott et al (2017a), há um empoderamento das mães ao incorporar conhecimentos jurídicos. O que a princípio poderia ser uma relação de reciprocidade entre Estado e cidadão, transforma-se numa arena de disputas desiguais, travando-se uma verdadeira batalha para conseguir garantir alguns direitos básicos. A judicialização, campo pouco abordado na economia política em saúde, tem sido, para algumas famílias, uma via de acesso a seus direitos.

Ao ser classificada como pessoa com deficiência, essa criança tem direito ao acesso a alguns benefícios sociais já previstos por lei como o Vem Livre Acesso, o Benefício de Prestação Continuada - BPC, o Minha Casa Minha Vida, além do Bolsa-Família. Contudo, embora tenham conseguido o direito a 'prioridade da prioridade', estas famílias de crianças com SCZ esbarram na falta de clareza sobre as documentações requeridas, na peregrinação por diversos órgãos e numa legislação pouco afeita à realidade de um cuidador de criança com deficiência.

Para se ter uma ideia dos paradoxos destas políticas públicas e benefícios assegurados a estas famílias, citamos, por exemplo, algumas questões complexas: (1) num país no qual a gravidez na adolescência é extremamente alta, é negada a titularidade do BPC a estas mães, empurrando-as ainda mais para vulnerabilidade por não terem autonomia de gerir este recurso nos cuidados de seu filho, tendo que repassar esta titularidade a um maior; (2) Por ser menor, também não poderá ser beneficiária do Bolsa-Família. Não poderá ainda ser computada 
no Bolsa Família de sua mãe, pois esta adolescente terá que comprovar $70 \%$ de frequência na escola, como previsto no Programa. Mas a pergunta que se faz é: com quem esta mãe deixará seus filhos para frequentar a escola?; (3) Para ser ter acesso ao BPC, segundo relato de algumas mães, elas precisam ser 'miseráveis', já que, o corte previsto corresponde a $1 / 4$ do salário mínimo, ou seja, a renda familiar não pode ultrapassar 234, 25 centavos; (4) Atualmente, devido às questões sociopolíticas do Brasil, tem sido comum o relato de algumas mães afirmando que a Bolsa-Família foi cortada por que estas já recebem o BPC. Contudo, já existe jurisprudência afirmando a legalidade em receber os dois benefícios, já que, um incide sobre a família e o outro é direito da pessoa com deficiência; (5) Ter o $\mathrm{BPC}^{4}$ não afasta as inseguranças e as angústias destas mães. Em decorrência desta titularidade, elas precisam se afastar de trabalhos com carteira assinada, impossibilitando-as da aposentadoria por tempo de contribuição. A estas também é vedada a contribuição ao INSS como dona de casa como nos exemplificou esta mãe:

"Eu tenho BPC do meu filho que é a única renda que eu tenho hoje, já que eu deixei de trabalhar pra me dedicar integralmente, 24 horas ao emprego de mãe. Com isso eu não posso pagar nem meu INSS nem como dona de casa, sabia? Aquela taxa de 28 reais, eu não posso pagar, porque eu tenho BPC. Vai cortar meu BPC, o INSS diz. Então assim, sabe o que é que vai acontecer? Eu desejo vida longa ao meu filho, mas se daqui a 15, 20 anos ele vir a falecer, eu não vou poder mais me aposentar. Quem é que vai querer empregar uma mulher de 45, 50 anos? E essa mãe vai viver como?"

A Avaliação do Impacto Socioeconômico do Vírus Zika na América Latina e Caribe, realizado pelo PNUD, em 2017, destaca que, mesmo o Programa de Proteção Social Bolsa Família fornecendo um benefício adicional para famílias de crianças com microcefalia, ainda não é suficiente para diminuir a situação de vulnerabilidade. É necessário que os sistemas de proteção social forneçam pacotes de benefícios que sejam proporcionais aos custos reais dos cuidados, assim como garantir oportunidades concretas de subsistência para as mães. 
Para se ter uma ideia do dinamismo das articulações do Estado e da sociedade civil organizada, reforçamos o papel das associações na cobrança por melhorias no atendimento às crianças com SCZ. Em 2015, apenas duas unidades na capital prestavam atendimento a elas: a Associação de Apoio de Assistência à Criança com Deficiência (AACD) e o Instituto de Medicina Integral Professor Fernando Figueira (IMIP). Em 2017, Pernambuco conta com 29 unidades espalhadas por todo Estado que prestam algum tipo de atendimento, além do setor privado. Algumas dessas unidades foram criadas motivadas pela situação emergencial da SCZ, outras tiveram que se adaptar para atender a demanda causada pelo Zika.

Outra necessidade encabeçada pelas associações e que afeta diretamente o campo econômico das famílias de crianças com SCZ, é o direito a creche. No Brasil, esse tem sido um grande desafio para gestão pública que não conseguiu garantir de fato esse acesso, principalmente para crianças com necessidades diferenciadas. Até o presente momento, os bebês com SCZ estão sem esse serviço, com pouquíssimas exceções, o que coloca suas cuidadoras numa situação mais vulnerável ainda. Como elas entrarão ou voltarão ao mercado de trabalho? Como irão continuar seus estudos? Como terceirizarão os cuidados?

No Brasil, seja pelas ausências de serviços de qualidade esperada, seja pelas intervenções não desejadas pelo Estado, criou-se uma situação que tem sido descrita por Scott $(2006 ; 2009)$ como 'insegurança administrada', o que ressalta ainda mais a importância do ponto de encontro Estado e cidadão para criar confiança multa. No que diz respeito à saúde, é evidente que a maneira que o Estado planeja as suas relações com comunidades afetadas por patologias específicas, e a maneira pela qual se envolve nas perspectivas desta população, pode implicar na geração de insegurança ou de confiança. Uma análise de surtos de patologias em outros lugares (Leach 2015) ilustra bem a maneira em que surtos pequenos podem aumentar rapidamente quando se desenvolvem em contextos de impedimentos e fracassos de sistemas de saúde e sistemas sociopolíticos maiores. 
Formação de redes: política, economia, poder e ciência atuando no caso do Zika

Para discussão de rede aqui apresentada nos baseamos em Bruno Latour (2013), para quem não há redes propriamente ditas, mas formação de redes, uma vez que elas estão sempre em movimento. Desta maneira, o autor enfoca as conexões que essas redes estabelecem e propõe seguirmos as trilhas deixadas pelos atores, para o nosso caso, pessoas impactadas pelo Zika, Estado, organizações não governamentais, pesquisadores, empresas, laboratórios.

Em busca de conexões, começaremos com o relato dos fatos da relação estabelecida entre o vírus Zika e o nascimento de bebês com microcefalia. Em 2015, a médica obstétrica, Adriana Melo, de Campina Grande, Paraíba, estampa manchetes de jornais, como sendo uma das primeiras profissionais que relacionou os casos de nascimentos de bebês com microcefalia à contaminação pelo vírus Zika. Em Pernambuco, profissionais também notificaram aos órgãos públicos o aumento do número de casos de microcefalia, iniciando assim um longo percurso dos pesquisadores em busca de fatos que comprovassem a hipótese. As respostas do Estado foram embasadas nos achados científicos que aquesceram, por sua vez, a economia política da saúde.

No caso do Zika, portanto, houve uma associação muito rápida entre fatos científicos e ações políticas, uma vez que decisões, prioridades e descobertas sofreram e vêm sofrendo efeitos políticos, ilustrando a afirmação de Latour \& Woolgar (1999) ao considerar que ciência é política.

O Estado, neste contexto, pode ser representado pelo Ministério da Saúde, órgão do poder executivo responsável pela organização e elaboração de planos e políticas públicas voltadas para a promoção, prevenção e assistência à saúde. Com o aumento dos casos, medidas emergenciais foram tomadas, verbas foram liberadas para ações pontuais e incentivo a pesquisas. O centro de pesquisa Ageu Magalhães, Fiocruz-Pernambuco, se destacou na formação de uma rede que foi essencial para a confirmação dos casos e proposição de medidas emergenciais em torno do Zika e da microcefalia. Formou-se o 
Grupo de Pesquisa da Epidemia da Microcefalia (MERG), composto por pesquisadores nacionais e internacionais de várias instituições. Sua rede inclui especialistas em epidemiologia, doenças infecciosas, clínicos, pediatras, neurologistas, biólogos e investigadores da saúde reprodutiva ${ }^{6}$. Duas conexões são importantes na formação desta rede, a conexão com o Estado, via Secretaria de Saúde de Pernambuco e Ministério da Saúde e com os clínicos que lidam diretamente com os bebês e suas famílias.

A descoberta em torno da relação entre vírus Zika e a microcefalia causou impactos internacionais chamando atenção para o grupo. Houve uma corrida científica em busca de fatos e relações, sobressaindo as pesquisas epidemiológicas e neurológicas, por conta da incidência da infecção pelo vírus na população pernambucana e em mulheres em idade fértil e pelo nascimento de bebês com Microcefalia. Verificando os artigos publicados pelo grupo disponíveis em seu site observa-se a tendência dos pesquisadores em provar que a carga viral presente em mulheres grávidas causa a Microcefalia. A criação de um sistema de notificação especial pelo Ministério da Saúde possibilitou o acompanhamento de mulheres gestantes infectadas pelo vírus, tornando-as objeto de ciência. Seus filhos são testados, acompanhados, medidos, observados constantemente. Chama atenção o artigo intitulado 'Risco de microcefalia relacionado a zika: estável ou instável' (Rodrigues \& Paixão 2017). Nele os autores comentam resultados de pesquisas que refletem sobre a diminuição da epidemia e os fatores que podem estar relacionados. A epidemia não teve à proporção que se imaginava, sendo muito rápida no nordeste brasileiro e lenta em outras regiões, influenciada, segundo os pesquisadores, pela densidade humana e pela variação do mosquito. Ainda, levantam a hipótese do aumento do fator de risco em decorrência da coinfecção por Zika, Dengue e Chikungunya.

As pesquisas proporcionam o conhecimento dos efeitos da síndrome, a descoberta de remédios e vacinas, organização de ações de prevenção e cuidados. Cabe destacar que uma das pesquisadoras fun- 
dadoras do MERG, Celina Turchi, foi eleita pela Revista Nature, uma das dez cientistas mais importantes em 2016, justamente pelo seu trabalho no grupo em busca da comprovação científica da relação entre o vírus e a Microcefalia. Ainda em 2016, a neuropediatra pernambucana, Vanessa Van der Linden, primeira profissional a identificar mudança no padrão de ocorrência da Microcefalia em Pernambuco, foi agraciada na categoria equidade social, no Leadership For The Americas Awards, do Inter-American Dialogue.

Tais ações têm movimentado milhares de reais em fomento tanto nacional como internacional de pesquisas. Apesar das excelentes pesquisas e sua importância para o campo das políticas públicas de saúde, apenas em 2017 o MERG apresenta pesquisa com foco em aspectos sociais do Zika. A pesquisa internacional Impactos Sociais e Zika, em parceria com instituições da Inglaterra e do Brasil, destaca as consequências econômicas nas famílias que tiveram filhos com SCZ.

Em 2015, o Ministério da Saúde lançou o Plano Nacional de Enfretamento à Microcefalia, criado pelo Grupo Estratégico Interministerial de Emergência em Saúde Pública, de importância nacional e internacional. Este grupo envolve 19 órgãos e entidades, abrangendo três eixos de ações: mobilização e combate ao mosquito, atendimento a pessoas, desenvolvimento tecnológico, educação e pesquisa. Em meio a tantos acontecimentos, foi criada, em 2016, a Rede Nacional de Especialistas em Zika e Doenças Correlatas (Renezika) ${ }^{7}$.

O trabalho em rede já é uma prática desenvolvida pelo setor da saúde no Brasil, mas no caso de emergências, as conexões das redes se intensificam. Pensando nessas redes como associações (Latour 2013), verificamos as dinâmicas estabelecidas em movimentos constantes com novas associações. Assim, a partir de determinada rede outras são associadas, como o Zikalab (Laboratório de Formação do Trabalhador de Saúde no Contexto da Microcefalia), que formou 300 profissionais da rede de saúde de Recife para atuar no enfretamento ao vírus Zika e suas consequências ${ }^{8}$. 
A rede não se restringe ao campo da saúde, mas envolve vários setores como a Assistência Social e o Judiciário. As políticas de assistência inserem as famílias em programas sociais já existentes e o judiciário, por meio do Ministério Público, da Defensoria Pública e da Ordem dos Advogados do Brasil (OAB), tentam garantir o exercício da cidadania para famílias que tiveram filhos com SCZ.

A confiança das pessoas afetadas pelo vírus nas ações do Estado é impactada pelo grau de respostas as demandas imediatas. Como exposto anteriormente, apesar de ser garantido o direito ao BPC à pessoa com deficiência, muitas famílias esbarram nas exigências, que são distantes da realidade vivenciada por elas, como por exemplo, ter renda mensal por membros da família igual ou inferior a $1 / 4$ do salário mínimo. Cabe destacar que o BPC para pessoas com deficiência é garantido na Lei Orgânica da Assistência Social (LOAS) desde 1993. Entretanto, a Portaria No 58, de 3 de junho de 2016, prevê estratégia de Ação Rápida para o Fortalecimento da Atenção à Saúde e da Proteção Social de Crianças com Microcefalia, nos seguintes termos:

"Estabelecer ações articuladas das redes de Assistência Social e do Instituto Nacional do Seguro Social - INSS no apoio ao processo de requerimento do Benefício de Prestação Continuada da Assistência Social - BPC, pelas crianças diagnosticadas com microcefalia, que disponham do laudo médico circunstanciado emitido pelo Sistema Único de Saúde - SUS, nos termos do art. 4 da Portaria Interministerial MS/MDS no 405, de 15 de março de 2016" 9.

As medidas emergenciais foram necessárias mediante a situação apresentada pelo aumento dos casos de crianças com SCZ. No entanto, a pesquisa Etnografando Cuidados tem demostrado que a existência e acesso a esses direitos são repletos de dificuldades. Algumas mães, por exemplo, não têm acesso ao laudo médico de seus filhos. Por outro lado, considerada uma deficiência, a SCZ entra num campo já estabelecido no seio das políticas públicas para pessoas com deficiência. A prioridade para as crianças com SCZ causou certo desconforto para as famílias que possuem crianças com outras deficiências, uma 
vez que também enfrentam dificuldades no acesso aos benefícios e tratamento de saúde. $\mathrm{O}$ campo da economia política precisa lidar com outras esferas, neste caso, as relações que estão se estabelecendo entre as múltiplas deficiências. Destarte, não se pode negar que os casos de Microcefalia chamaram atenção para deficiências historicamente já conhecidas (Scott et al 2017a).

Em março de 2017, no encontro nacional da Renezika, o Ministro da Saúde, Ricardo Barros, anunciou o investimento de 135 milhões em pesquisas e centros de reabilitação para estimulação de crianças com microcefalia e outras alterações associadas ao vírus Zika. Além da rede de habilitação, o Programa de Saúde da Família terá verba para formação de equipes para atuar na estimulação precoce. Se, por um lado, existe o investimento do Estado para as crianças com SCZ, por outro, observa-se, mobilizado pelo atual contexto político brasileiro, a falta de investimento no Sistema Único de Saúde (SUS). Estão previstas mudanças na gestão do SUS, com menos verba destinada a atenção primária, o que impactará as crianças com SCZ e suas famílias, principalmente após o anúncio do fim do estado de emergência pública para o Zika.

As arboviroses e mais especificamente o vírus Zika e seus desdobramentos na população, tornou-se alvo de movimentado mercado político e econômico que realçou as relações de poder e debates acadêmicos antagônicos evidenciados em agosto de 2017, na primeira Feira de Soluções para a Saúde - Zika, em Salvador. Este evento, idealizado pela Fiocruz em cooperação com o Ministério da Saúde, teve como objetivo "criar espaços de diálogos regionais e ativar redes de cooperação para a apresentação e difusão de inovações tecnológicas, sociais e de serviços de saúde voltadas à Zika, Dengue e Chikungunya, no com-

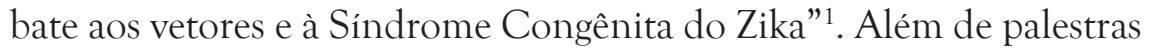
com temáticas diversas, este evento abriu espaço para diversos atores apresentarem soluções em serviços, sociais, industriais e tecnológicos.

Embora a proposta da Feira de Soluções para a Saúde - Zika tenha sido pioneira, ela não deixou de despertar críticas por sua ênfase 
mercadológica e mosquitocêntrica. Dez dias após o término da Feira, o Grupo Temático Saúde e Ambiente da Associação Brasileira de Saúde Coletiva (GTSA/Abrasco), lançou nota crítica contra a ação de lobbies de interesse mercadológico e frente ao patrocínio da Oxitec na Feira de Soluções para a Saúde - Zika. Além da crítica ao teor mercadológico das discussões ocorridas na Feira, o acirramento do debate apontou ainda a ausência de temas que tratassem da tríplice epidemia, "tais como o saneamento ambiental, a determinação social da saúde, o problema das intoxicações provocadas pela exposição a agentes químicos utilizados no controle vetorial (crítica ao modelo de controle químico) e a ausência de estudos de médio e longo prazo sobre o uso de mosquitos geneticamente modificados e afins" (Schütz 2017).

Soma-se ainda a este debate, a crítica a falta de participação mais efetiva das famílias acometidas pela SCZ que tiveram pouco espaço na construção e/ou validação das soluções apresentadas nesta Feira. O resultado é que no último dia do evento, a Associação de Famílias com Crianças Portadora de Microcefalia e Outras Más Formações Congênitas da Bahia (ABRAÇO) protagonizou um grande protesto no evento. Ao reafirmarem as condições de extrema vulnerabilidade que passam, ressaltando a falta de creches, medicamentos, profissionais de saúde, realidade esta, não muito diferente do que acontece em outros Estados do Brasil, uma das mães finalizou seu discurso afirmando que o "Estado é responsável por nossos filhos terem nascido com Microcefalia e nós não vamos aceitar nada a menos que os nossos direitos" ${ }^{10}$.

Destacamos que a participação das famílias nesse processo é fundamental. As redes domésticas em torno do cuidado com a SCZ envolvem vários indivíduos, são pais, mães, avós, amigos, profissionais de saúde, da assistência social, religiosos. Essas redes e suas diversas associações (Latour 2013) adquiriram experiências que precisam ser incorporadas nas ações políticas de enfretamento ao Zika. Não por acaso o relatório de Avaliação do Impacto Socioeconômico do Vírus Zika na América Latina e Caribe, aponta a participação da comuni- 
dade como um eixo fundamental no enfrentamento às desigualdades potencializadas pela epidemia.

Integrantes dessa grande rede em torno do Zika, as associações de mães e cuidadoras, têm assumido importante papel de mediadores entre as mulheres e o Estado. Tanto na UMA como na AMAR, as mulheres encontram apoio para enfrentar as experiências advindas dessa nova situação. Nesse sentido, as mulheres, mães desses bebês, buscam estratégias para compreender melhor a situação que experimentam. Elas formam associações, criam grupos de whatsApp, blogs, páginas no Facebook que possibilitam, entre outras coisas, a ampliação de suas relações, ou da própria rede (Scott et al 2017a). No caso da UMA, a ferramenta do whatsApp serve para conectá-las com mulheres do interior do estado ampliando assim sua rede.

A importância dessas associações é apontada por Diniz, entre outras coisas, por se constituir como espaço de produção de uma "ciência doméstica do cuidado que se move paralela à ciência oficial da medicina" (2016:10). Este paralelismo inclui a detecção de outros efeitos associados, tais como as convulsões e deficiências visuais e auditivas, cujo diagnóstico muito se deve a observação das mães em sua rotina de cuidado com os filhos. A conexão, que pode ser estabelecida entre ciência e conhecimento prático doméstico, pode ser uma ferramenta importante no cuidado com as crianças com SCZ e no estabelecimento de políticas públicas de saúde mais efetivas. Nesse sentido, os centros de reabilitação são fundamentais para pensar a qualidade de vida dessas crianças, e perspectivas como as de Ingold (2010), para quem o desenvolvimento humano está além da dicotomia entre capacidades inatas e adquiridas, sendo o resultado de um engajamento dinâmico no ambiente, podem apresentar outros caminhos possíveis no campo da cognição e desenvolvimento de habilidades marcadas por condições congênitas. Espera-se que essas crianças se tornem jovens, adultos e, desta forma, não poderão ser vistas apenas por uma lógica mercadológica, como pessoas que estarão fora do mercado de trabalho, um peso para o Estado. 
A perspectiva de Ingold (2007) de repensar a relação entre humano e não humano de forma mais colaborativa do que conflitiva, pode contribuir para repensarmos a relação estabelecida entre o mosquito e as pessoas. A crítica ao modelo mosquitocêntrico é pertinente porque grande parte dos investimentos e empenho tecnológico tem sido destinada a ele, deixando de lado as pessoas. A Oxitec, por exemplo, tem investido muito dinheiro em tecnologias para produção de mosquitos geneticamente modificados com fábricas instaladas no Brasil. Como mostram algumas pesquisas, a variabilidade do mosquito é um dos fatores que influencia o perfil epidemiológico das arboviroses (Rodrigues \& Paixão 2017) e medidas unilaterais não darão conta da complexa rede estabelecida no ambiente entre o mosquito e os seres humanos. A economia política do Zika deve atentar também para relações interespecíficas, uma vez que a extinção do Aedes aegypti parece uma possibilidade remota e pesquisas recentes da Fiocruz (Guedes et al 2017) apontam que o vírus Zika pode também ser transmitido pelo mosquito Culex (pernilongo).

Como podemos observar, a rede formada a partir do Zika está se ampliando, sendo difícil descrever todas aqui neste artigo. Queremos chamar atenção para as ações que envolvem a economia política em torno do cuidado, do campo científico e do atendimento em saúde, afetando as relações entre Estado e cidadão. São relações de poder, num campo em que se disputam protagonismos.

\section{Considerações finais}

Os casos de Microcefalia exigiram uma atenção especial de pesquisadores e profissionais de saúde para a compreensão e proposição de atendimento e tratamento eficazes, entretanto, o conhecimento dos efeitos do Zika no organismo humano, para o contexto do Brasil, ainda está em construção, daí o esforço do Estado em financiar pesquisas que auxiliem as ações políticas.

Apesar de tanto investimento em tecnologias, como aplicativos que identificam lugares de risco para proliferação do mosquito, pes- 
quisas e ações governamentais, a efetividade e o alcance das medidas tomadas ainda precisam ser avaliadas. A decretação do fim do estado emergencial não traz certeza quanto a resolução das consequências para a população. $O$ fato está diretamente relacionado a uma diminuição acentuada dos casos notificados e confirmados, devido a ênfase acentuada no combate ao Aedes aegypti e não às pessoas afetadas pelo mosquito. Entretanto, ainda há muito a se descobrir sobre as consequências do vírus Zika e seu impacto na economia política do cuidado e do atendimento em saúde. O relatório de Avaliação do Impacto Socioeconômico do Vírus Zika na América Latina e Caribe (PNUD 2017) traz algumas propostas interessantes como: atenção especial para ocorrências de múltiplas infecções, Dengue, Chikungunya e Zika; promover equidade e proteção social as pessoas afetadas; promover políticas públicas que apoiem a igualdade de gênero e promovam a saúde e os direitos sexuais e reprodutivos, tendo como alvo as comunidades afetadas.

Sabe-se que as pessoas afetadas pela Chikungunya ficam com sequelas relacionadas a dores nas articulações, mas ainda há muito a se descobrir a respeito do comportamento do Chikungunya e do Zika no organismo humano. Em participação no workshop realizado pela pesquisa Etnografando Cuidados, em maio de 2017, na mesa redonda 'Cuidados, atendimentos e direitos: diálogos intersetoriais sobre Zika', a presidente da UMA, mãe de uma criança com SZC, grávida de quatro meses, relatou: "eu estou grávida de quatro meses e meu bebê já está sendo alvo de várias pesquisas, uma vez que o vírus ainda está ativo em mim e não se sabe as consequências”.

Por outro lado, as certezas conquistadas com pesquisas são sempre provisórias. Se havia certeza de que o vírus só seria transmitido para o feto nos três primeiros meses, ela tem sido questionada por alguns pesquisadores. A transmissão pela via sexual para a grávida tem sido uma das fontes de questionamento pouco abordado pelo poder público, mas enfatizado pelos movimentos feministas. Além disso, descobriu-se recentemente, que as consequências neurológicas 
se potencializam, quando o Zika, a Chikungunya e a Dengue se associam em uma mesma pessoa. No caso do Zika, o grande investimento em pesquisas, tem resultado numa ampliação de conhecimento das consequências para o corpo humano, em termos da transmissão de doenças, mas também realçado aspectos políticos em torno das práticas de pesquisas científica voltadas para intervenção. Nesse sentido, é de suma importância a ampliação da rede de pesquisas para abarcar outros campos, como as ciências sociais, e também a incorporação do conhecimento desenvolvido pelas cuidadoras em suas práticas cotidianas de cuidados.

Diante do atual contexto social, político e econômico em torno do Zika, é necessário examinar as maneiras pelas quais as agências nacionais e internacionais têm organizado as suas diferentes ações. Epidemias trazem consequências graves para a saúde e interferem em políticas sociais e econômicas dos Estados. Apesar de o Brasil ter apresentado respostas rápidas, principalmente nos setores de pesquisa e atendimento, é preciso atuar nos efeitos menos evidentes, como nos impactos sociais e emocionais, nas perdas e dificuldades econômicas.

\section{Notas}

1 Consultar 'Informe Técnico - n 21/2017, Síndrome congênita relacionada à infecção pelo vírus Zika Período de Referência: SE 30/2015 (26/07/15 a 01/08/15) a SE 42/2017 (15 a 21/10/2017)'. Dados atualizados até: 24/10/2017. (https://docs. wixstatic.com/ugd/3293a8_833d12b09cd64d9b9b764c4f1eacd3fb.pdf; acesso em $31 / 10 / 17)$.

2 O vírus Zika causa febre, cefaleia, exantema, as chamadas manchas vermelhas, dores articulares e edemas. Ainda não se sabe os efeitos do Zika no organismo humano por longo período.

3 São raras as exceções de políticas públicas voltadas especificamente para o cuidador da pessoa com deficiência. Fruto da participação ativa das famílias com doenças raras, incluindo a SCZ, ocorreu, no dia 23/08/17 em Recife, uma audiência pública da Comissão de Cidadania da ALEPE, para debater o Projeto de Lei no 1416/2017 que visa instituir uma política estadual de proteção, valorização e 
habilitação do cuidador com laços afetivos. O Projeto de Lei da Deputada Estadual Socorro Pimentel é fruto de intenso diálogo com a ONG Aliança das Mães e Famílias Raras - Amar.

4 O valor do BPC é de um salário mínimo.

5 Relato de uma mãe que tem a SCZ, em 24/05/17.

6 Para mais informações ver, http://www.cpqam.fiocruz.br/merg/. Acesso em 15.05.2017.

7 Para mais informações ver: http://renezika.org/portal/institucional/historico. Acesso em 15.05.2017.

8 Para maiores informações: https://www.researchgate.net/project/ZikaLab. Acesso em 20.05.2017.

9 MINISTÉRIO DO DESENVOLVIMENTO SOCIAL E AGRÁRIO GABINETE DO MINISTRO.DOU de 06/06/2016 (nº 106, Seção 1, pág. 55).

10 Relato de uma mãe com filho com SCZ, no dia 10/08/17, durante o protesto realizado pela ABRAÇO, na Feira de Soluções em Saúde - Zika em Salvador.

\section{Referências}

ALVES, Paulo Cesar. 2015. "Política \& Trabalho". Revista de Ciências Sociais, 42:29-43.

AYRES, José R. 2009. Cuidado: trabalho e interação nas práticas de saúde. Rio: CEPESC - IMS/UERJ - ABRASCO.

BELLUZZO, L. 2005. Ensaios sobre o Capitalismo no Século XX. São Paulo: Editora Unesp.

CARRASCO, Cristina. 2012. "O paradoxo do cuidado: necessário, porém invisível”. In JÁCOME, M. \& VILLELA, S. (eds.): Orçamentos Sensiveis a Gênero: conceitos, pp. 251-285. Brasília: Onu Mulheres.

CORNWALL, A. \& SHANKLAND, A. 2008. "'Engaging Citizens: Lessons from Building Brazil's National Health System'”. Social Science $\mathcal{E}$ amp; Medicine, 66(10):2173-84.

DINIZ, Débora. 2016. Zika: do Sertão nordestino à ameaça Global. Rio de Janeiro: Civilização Brasileira.

GERHARDT, T. E. 2006. "Itinerários terapêuticos em situações de pobreza: diversidade e pluralidade". Cad. Saúde Pública, 22 (11):2449-2463.

GUEDES, D. R. D. et al. 2017. "Zika virus replication in the mosquito Culex quinquefasciatus in Brazil.” Emerging Microbes $\mathcal{E}$ Infections, 6:1-11.

HIRATA, H.S. 2012. "O desenvolvimento das políticas de cuidados em uma perspectiva comparada: França, Brasil e Japão". Revista de Políticas Públicas, 16 (Número Especial):283-290. 
INGOLD, Timothy. 2010. "Da transmissão de representações à educação da atenção." Educação, 33(1):6-25.

. "Introdução. O que é um animal". Antropolítica: revista de antropologia contemporânea, 22:129-150.

LATOUR, Bruno. 2013. Reagregando o Social: uma introdução à teoria Ator-Rede. São Paulo: EDUSC/EDUFA.

LATOUR, B. \& WOOLGAR, S. 1999. A Vida em Laboratório: a produção dos fatos cientifico. Rio de Janeiro: Relume Dumara.

LEACH, Melissa. 2015. "The Ebola crisis and post-2015 development". Journal of International Development, 27:816-834.

JONES, C. O. \& WILLIAMS, H. A. 2004. "The Social Burden of Malaria: What are we measuring?" The American Journal of Tropical Medicine and Hygiene, 71(2 Suppl):156-61.

MEIRA, F. et al. 2017. A experiência das mulheres cuidadoras de crianças com a Síndrome Congênita do Zika e suas articulações e desarticulações com o Estado. Trabalho Apresentado no XVI Congresso Brasileiro de Antropologia en Colombia. V Congreso Asociación Latinoamericana de Antropologia, Bogotá - Colômbia.

MIRANDA-FILHO, D. B. et al. 2016. "Initial description of the presumed congenital Zika syndrome." Am J Public Health, 4:598-600.

PEREIRA, D. \& LONGHI, M. 2017. "Maternidade como missão! A trajetória militante de uma mãe de bebê com microcefalia em PE". Cadernos Gênero $e$ Diversidade, 03(02):113-133.

PINHO, P. A. \& PEREIRA, P. P. 2012. "Itinerários terapêuticos: trajetórias entrecruzadas na busca por cuidados". Interface (Botocatu), 16(41): 435-47.

PNUD. 2017. Uma Avaliação do Impacto Socioeconômico do Vírus Zika na América Latina e Caribe: Brasil, Colômbia e Suriname como estudos de caso.

RODRIGUES, L. \& PAIXÃO, E. 2017. "Risk of Zika-related microcephaly: stable or variable?". Published online, June 21. (http://dx.doi.org/10.1016/S01406736(17)31478-2; acesso em 31/10/17).

SCHÜTZ, Gabriel. 2017. Crítica ao patrocínio da Oxitec ao evento 'Feira de Soluções para a Saúde - Zika'. (www.abrasco.org.br/site/noticias/movimentos-sociais/ oxitec-feira-zika-salvador/30194/; acesso em 31/10/17).

SCOTT, R. P. 2006. "Re-assentamento, saúde e insegurança em Itaparica: um modelo de vulnerabilidade em projetos de desenvolvimento". Saúde e Sociedade, 15(3):74-89. . 2009. Negociações e Resistência Persistentes: agricultores e a barragem de Itaparica num contexto de descaso planejado. Recife: Editora Universitária da UFPE.

SCOTT, R. P. et al. 2017a. "A Epidemia de Zika e as Articulações das Mães num Campo Tensionado entre Feminismo, Deficiência e Cuidados." Revista Cadernos de Gênero e Diversidade, 03(02):73-92.

2017b. "Itinerários terapêuticos, cuidados e atendimento na construção de ideias sobre maternidade e infância no contexto do Zika." Interface, (no prelo). 
VIANA, A. L. et al. 2007. Economia política em saúde: introduzindo o debate. Texto apresentado na 2a Jornada de Economia da Saúde - Abres. Belo Horizonte - MG.

\begin{abstract}
The Zika epidemic and its relationship with the birth of children with microcephaly brought great challenges to global public health. In Brazil several efforts have been made to minimize its consequences by mobilizing important sectors of health, science, the pharmaceutical industry and the family economy. This article intends to discuss the political economy of the zika focusing on the relations established between the State and the citizen with regard to care and attendance. It focuses on the context of vulnerability of affected families in a process of overlapping social and economic inequalities, in which women, mothers and caregivers bear the greatest social burden of the epidemic.
\end{abstract}

Keywords: Zika; Economy; Health.

Recebido em agosto de 2017.

Aprovado em setembro de 2017. 